\title{
GÉNERO GRAMATICAL Y MOTIVACIÓN SEMÁNTICA
}

\author{
ANÍBAL ARIAS BARREDO \\ (Universidad de Valladolid)
}

Empezaremos por admitir metodológicamente - según otro estudio nuestro en vías de publicación-- que el rasgo [ \pm anim.] es operativo desde el punto de vista motivacional del género en el sistema de la lengua española. De ahí que, en el presente, arranquemos, sin más introducciones, de esa distinción tomada como postulado de base para proceder al estudio de los nombres de seres animados, o sea, de las clase [+ anim.]. Los nombres pertenecientes a la clase [- anim.] serán objeto de otro trabajo.

\section{El Género de los nombres de seres animados.}

El hecho de que sea posible distinguir dos niveles de estructuración semántica con relación al género gramatical dentro de la parcela marcada por [+ anim.], como muestra el esquema (1), e. d., que sea posible hablar de una parcela sin oposición morfemática ni flexión posible, de carácter [-esp.], y de otra en que los géneros gramaticales se dan a simultáneo con oposición semántica sexuada, de carácter [+ esp.], permite a su vez establecer la diferenciación metodológica de sendas parcerlas, aunque sólo sea con fines de estudio e investigación. Y así lo hemos hecho nosotros para el presente. 


\section{labrador}

agricultor [-esp.]

segador Se interpreta como Agente de, e incluye a hombres y mujeres.

\section{labrador/labradorA}

agricultorlagricultorA [+esp.]

segador/segadorA Se interpreta como Ag de, y opone los hombres a las mujeres, en virtud de la distinción de sexo, marcado por la -A final de femenino (' $f$ ').

\section{Veamos el siguiente texto de Torrente Ballester:}

«La sierpe llegó enseguida, como de paso. Dijo: «Estás muy guapa, Eva», y siguió serpeando por la vereda. Pero Eva la detuvo [...] La serpiente le preguntó qué tal lo pasaba con Adán [...]

- Lo más bonito de todo - dijo- es que yo siento mi goce en el de Adán. Y él dice que le pasa lo mismo con el mío [...]

- LO mismo me sucede a mí con mi culebrO.

$$
[\ldots]
$$

- ¿No has advertido [-dijo la culebrA-] que, si una noche tu macho está cansado y se duerme [...] Los machos cuando están cansados prefieren dormir. Pero si el placer fuese para nosotrAs solAs, los machos no se fatigarían, porque, así como a nosotrAs nos embellece, a ellos les da vigor».

(G. Torrente Ballester, D. Juan. Destino, Col. Destino-libro, Vol.14)

El juego oposicional que presenta este texto entre Adán/Eva, culebro/culebra (sierpe), machos (ellos)/[hembras] nosotras, pone bien a las claras que el «sexo» es un fuerte operador semántico de género gramatical, a pesar de que él no lo sea. En nuestra tradición, estuvo muy arraigada esta idea de motivación linguística, contra la que constantemente se ha luchado, no por creerla falsa, sino más bien por descartarla como motivación única. Y pensamos que con toda razón. Pero también pensamos que nos hemos pasado en desvirtuar su recto sentido. Sería más justa, si no nos engañamos, una revalorización de actitud, como la que pretendemos establecer en este tarbajo.

«Genera nominum -escribía Consentio-quae naturalia sunt, duo sunt... masculum et feminum, quoniam omne scilicet animal natura necesse est esse masculum aut feminum...»l.

' Ramajo Caño, Antonio (1987): Las gramáticas de la lengua castellana desde Nebrija a Correas, Univ. de Salamanca, p. 96. 
Cuando el Brocense razona el rechazo de los nombres de género común, su razonamiento es a través de la motivación de «sexo». Dice:

«Pues si no existe ningún animal que tenga los dos sexos con igual fuerza, falso habrá de ser el nombre que no sea así, al designar el nombre de la cosa» ${ }^{2}$.

Así, Correas escribía también:

«Los géneros son tres: masculino, feminino ineutro. El masculino para el varón o macho i los nombres que le siguen. El feminino para la hembra i los de su vando...

«Estos géneros se conocen con los artículos que se ponen antes de los nonbres...

«Nombres hay que llaman en latín comunes a dos que sirven al macho y a la henbra.... $»^{3}$

No quisiéramos silenciar la postura del Licenciado Villalón, porque contiene todos los elementos que han constituido la clave de nuestro desarrrollo a lo largo de este epígrafe ${ }^{4}$. Del cap. III, pp. [18] a la [35] tomamos los siguientes fragmentos, que luego comentaremos:

«Es de notar que, aunque este vocablo, Genus en latín quiera dezir muchas cosas, pero tratando del género del nombre quiere decir propiamente naturaleza, linaje.

«[...] cuando preguntáremos un nombre de qué genero es, queremos decir, a qué linaje o naturaleza convenga su significación».

«Y pues en la generación hay dos maneras de linaje, como MACHO y HEMBRA, es nuestra intinción preguntar si tal nombre conviene en su significación al macho, o a la hembra».

«Y ansí digo, que tres géneros solos hay del nombre en la lengua Castellana, y no más. Quiero decir, que todos los nombres que en la lengua castellana hay, o conviene por su significación al MASCULINO, que es MACHO. O convienen al FEMENINO, que es la HEMBRA. O son del COMUN de dos: porque convienen por significación a ambos dos MACHO y HEMBRA».

Además de este criterio de significación, claramente semántico, establece Villalón otro criterio formal o de diferenciación gramátical, que consiste o bien en la «mudanza de la letra final» o más explícitamente en la anteposición de «los artículos ESTE, ESTA, AQUEL, AQUELLA, en el singular»:

«De manera que ESTE y ESTOS denotan el género masculino para señalar los nombres que convienen o significan el macho, o machos. Y ESTA y ESTAS denotan el género femenino para señalar los nombres que convienen y significan la hembra, o hembras».

Los textos creemos hablan por sí solos. En ellos pensamos ver:

\footnotetext{
2Brocese: Minerva, Introducción y trad. de Fernando Riveras Cárdenas, Ed. Cátedra, Madrid, 1976, p. 64

${ }^{3}$ Ramajo C., l. c., p. 103.

+ Tomamos para resumen los textos de su Gramática castellana (1558), editada port Constantino García bajo el título: Gramática castellana, Ed. Facsimilar y estudio de Constantino García, C.S.I.C., Madrid, 1971.
} 
a. Una clara referencia al género como indicador del sexo («el género masculino» para los nombres que significan el «macho»; «el género femenino» para los nombres que significan la «hembra»; y el «común de dos» para los que significan a ambos dos en forma simultánea).

b. Como corolario de lo anterior, aparecen implícitos dos criterios de determinación semántica: 1) Uno extensional que toma en cuenta los relata del género, según los nombres designen: (i) el conjunto de machos y hembras juntamente; (ii) sólo el conjunto de los machos; (iii) sólo el conjunto de las hembras. 2) Otro criterio intensional, según que la naturaleza de los designata sea especificada o no a través de los rasgos ' $\mathrm{M}$ ' o ' $\mathrm{H}$ ', o ni ' $M$ ' ni ' $\mathrm{H}$ ' pero ('M'+ 'H').

A pesar de que no aceptemos, naturalmente, el género «común» desde el punto de vista gramatical, por mostrarse dentro de una neutralización semántica hiperónima, que se polariza hacia uno de los dos géneros ' $m$ ' o ' $\mathrm{f}$ ', la distinción la vemos perfectamente adecuada. Ya la dejamos esbozada a nuestro modo en (1).

b. Se aprecia además en el texto de Villalón una definición del género desde las perspectivas semántica (de semántica referencial, con relación a sexo, como vimos), morfológica (con «mudanza» y «sin mudanza de la letra final») y sintáctica (entendida como técnica de reconocimiento, cifrada en la presencia del «artículo»= demostrativo).

c. También se halla el pensamiento de que, aunque el género es inherente al sustantivo, su determinación es de carácter distribucional, y, por lo tanto se da en el discurso (en sus palabras: «en lo común manera de hablar»).

d. En virtud de este criterio distribucional, proyecta el género natural (= sexo) hasta el género gramatical (básicamente combinatorio). Así puede sacar una conclusión del todo verdadera (la existencia de los géneros en los nombres de seres no sexuados) a través de un hilo inconsecuente (como ampliación del sexo a seres carentes de él). He aquí sus palabras: «Ansí dezimos ESTA muger, esta tabla».

\section{Animación, sexo, género.}

No es que nosotros pretendamos hoy poner el «sexo» como pedestal único e inconmovible para construir una teoría del género. Pero estamos convencidos de que negarlo tozudamente como una motivación fundamental y generalizadora, representa negar una buena razón histórica y científica que el mismo sistema del español nos impone constantemente con creaciones analógicas dentro de su ámbito semántico, e. d., dentro de la clase léxica de los nombres 'animados' pertenecientes a la subclase de los 'sexuados', tanto que se trate de humanos como de animales. 
Nuestra proposición consistirá en distinguir un triángulo semántico construido sobre la oposición genus/species. En él, el vértice superior corresponde al genus, esto es, el término hiperónimo o de extensión total, e. d., el que los gramáticos tradicionales conceptuaban como «común a dos» (y que incluye los «epicenos» y «comunes»). Por su carácter general, en adelante lo consignaremos [- - esp.]. Los dos vértices inferiores son el lugar adecuado para ambos términos de la oposición semántica, especificados como ' $M$ ' / ' $H$ ', que se especifican lingüísticamente a través de las formas expresivas del género ' $m$ '/'f'. Así se genera una doble oposición de dirección:
a) $[$-esp./+esp.]
b) [+esp./+esp.]

que se puede ejemplificar en el léxico de (2).

(2)

i. niñol/niñola, hombrel/hombre/mujer,...

ii. médico//médico/a. estudiantel/estudiantela $\simeq$ ellla estudiante, ellla cónyuge, pero cónyuge/*cónyuga, etc.

iii. artistal/artista/o, modistall?modisto/modista.

$i v$. perrol/perrola, elefantellelefantela,...

v. león//león/a, culebral/?culebrola, gorilal/el/la gorila,...

El registro pudiera hacerse limitado; pero no lo creemos ni necesario ni rentable. Lo que pretendemos es trasmitir la idea que ya dejamos expuesta de que el «sexo» es una motivación tan fuerte frente al género que da origen a creaciones de uso como culebro y modisto, que son sistemáticamente adecuadas. Para explicar este fenómeno —que Echaide denomina «tendencia a la moción» ${ }^{5}$ y Martinet entendería como «presión» ${ }^{6}$ del sistema-, pensamos que es necesario acudir a una figura semántica que nos permite hablar a la vez de inclusión y diferenciación, ambos conceptos presentes en las oposiciones que dejamos señaladas. Nos referimos a la hiponimia, concepto propuesto por Lyons (1963) siguiendo a Bazell7 .

Aceptaremos, pues, que ' $m$ ' y ' $f$ ' son hipónimos de «género», y que ambos se oponen entre sí en cuanto especificadores y cohipónimos de la oposición sexuada 'M' / ' $\mathrm{H}$ ' en los nombres de animales y personas, y, además, que se neutralizan a nivel de Hiperonimia. Para objetivar de alguna manera nuestra idea, emplearemos el ideograma triangular (3) en la forma que sigue:

${ }^{5}$ L. c., p. 132.

${ }^{6}$ Economía de los cambios fonéticos, Gredos, Madrid, 1974, 2.27 y 6.2.

${ }^{7}$ T. Levandowski, Diccionario de lingüística, Catedra, Madrid, 1982; y J. Lyons, Semántica, Teide, Barcelona, 1980, pp. 273 y ss. Siguiendo a estos autores, entendemos por hiponimia la relación semántica de inclusión; hiperónimo es el término genérico para hiónimo/cohipónimos; cohipónimos, términos que pertenecen a un mismo género (semántico). 


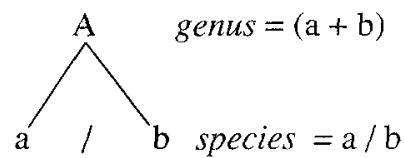

Digamos que A representa el término neutro o genérico desde el punto de vista semántico. Extensionalmente equivale al conjunto de los relata o referentes extralingüísticos y/o metalingüísticos, es decir que $\mathbf{A}=(\mathrm{a}+\mathrm{b})$ significa, en nuestro caso,

a. Semánticamente: SEXO = ('M' + 'H').

(«sexo» se entiende como el conjunto de los 'machos' ('M') más el de las 'hembras' ('H')).

b. Gramaticalmente: GÉNERO $=($ ' $m$ ' + 'f').

(«género» se interpreta como conjunto de 'masculino' ('m') más el del femenino (' $\mathrm{f}$ ')).

En cuanto a la forma de expresión de esa sustancia semántica linguística y/o metalingüística, simbolizadas por $a$ y $b$, e incluidas en $\mathbf{A}$, el género gramatical tiene a nivel sustancial que hemos llamado genus -y siguiendo para ello las nociones filosóficas aristotélicas - una forma y un género gramatical fijo. Puesto que la extensión semántica cubre ambos sexos, la motivación lingüística se neutraliza y el uso ha fijado cualquiera de las formas expresivas básicas generalizantes de las que dispone el español, y que tipificamos a nivel de sistema por $-o /-a$.

Muchas veces falta la marca $-o$, en cuyo caso los autores - entre ellos, Hjelmslev en la totalidad de su obra — hablan de la unidad $\varnothing$, aunque, como ya vimos, J. A. Martínez la rechaza9.

A nivel genérico de $\mathbf{A}$ los nombres del español suelen fijarse como masculinos terminados en - o o en - $e$, y como femeninos en - a. Pero la falta de una motivación semántica de sentido unidireccional ha llevado a fijar esos nombres en uno de ambos géneros bajo la influencia de la terminación (para el ' $\mathrm{f}$ ' los terminados en /-a/, para el ' $m$ ' el resto) o bajo la influencia del género etimológico (conservando el género de la lengua original). De todos modos, es difícil encontrar una arbitrariedad completa.

Así:

a. De acuerdo con la terminación,

-Son masculinos: $h o m b r e=($ varones y hembras $)$, león $=($ machos y hembras $)$, topo $=($ machos y hembras $)$, perro $=($ machos y hembras $)$, etc.

- Son femeninos: oveja $=$ (machos y hembras), llama = (machos y hembras), rata $=($ machos y hembras $)$, boa $=($ machos $\mathrm{y}$ hembras $)$, etc.

${ }^{8}$ Véase la aplicación de estas nociones por Aristóteles a la explicación de la metáfora en Artes poéticas, Ed. bilingüe de Aníbal González, Taurus, Madrid, 1987, pp. 80-81.

${ }^{9}$ Nosotros emplearemos en adelante este símbolo/- $\varnothing /$ para representar la pura ausencia de una marca, sin entender en ningún caso forma alguna del español. 
b. Se apartan de la terminación por otras razones (etimológica, histórica, etc. -Los masculinos: poeta $=$ (hombres y mujeres), artista $^{10}=$ (hombres y mujeres), socialista $=$ (hombres y mujeres $),$ gorila $=($ machos $y$ hembras $)$, etc.

Pero en este campo de lo sexuado no se dan nombres femeninos en - 0 . La razón es muy sencilla: No hay nombre femeninos en -o a nivel de A, e. d., [--esp.], porque el femenino, como término marcado, repugna y contradice un uso generalizante, ya que su función semántica es especificadora de oposición, o sea, actúa como diferenciador semántico de carácter cuantitativo o comprehensivo dentro de la sustancia común del contenido.

En cambio el femenino sí puede ser incluido en el masculino a nivel de $\mathbf{A}$ (no a nivel de $a$ ) porque $\mathbf{A}$, como término no marcado opera extensinalmente, desde afuera. Coseriu en «Relaciones de «significación» y relaciones de «designación»»" , estudia estos fenómenos como casos que "pueden llamarse designación de lengua», es decir de «relación entre un signo y la clase de objetos a la que designa (independientemente de las interferencias de las clases)». En estos casos, entendemos que es muy diferente la designación del conjunto a nivel de $\mathbf{A}$, de la designación de los elementos constitutivos del mismo, a nivel de $\mathbf{a} / \mathbf{b}$; ya que, a nivel de $\mathbf{A}$, «los significados lingüísticos no coinciden con las clases de designata» porque, en realidad, no designan ninguna en particular, lo que sí se hace a nivel de $\mathbf{a} / \mathbf{b}$. Uno de los ejemplos que presenta Coseriu es hijo//hijo/a, gráficamente:

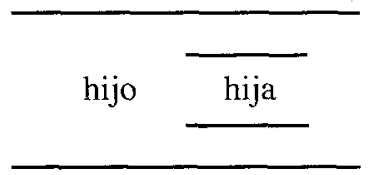

Este es el fundamento sobre el cual hay que entender las clases de nombres incluidos tradicionalmente como de género «común» y/o «epiceno», clasificación correctísima desde la perspectiva de distinción entre género natural (sexo) y género gramatical (género).

Nuestras conclusiones las vemos corroboradas por otros autores como el

\footnotetext{
${ }^{10}$ Es curiosa la explicación que da al género de este término José Manuel González Calvo («El género, ¿una categoría morfológica?», Anuario de Estudios Filológicos, II, Univ. de Extremadura, Cáceres, 1979 , p. 66). La falta de diferenciación de estos dos niveles semánticas lo lleva a escribir que «Artista implica género, pero no lo implica ni léxica ni morfológicamante» [ide acuerdo!]. Lo que no es correcto, por inconsecuente, es el razonamiento: «Es cierto - escribe-que, léxicamente, por poseer un rasgo 'humano', supone el contenido de 'sexo', pero también supone los contenidos de 'una nariz', 'dos ojos', etc.: no es esto un problema de género, ya que artista no indica el tipo de sexo, como lo indica loro, mujer, gata, etc.» Justo, porque estos tres términos van marcados como [+esp.], en tanto que artista lo analiza a nivel [- esp.].

${ }^{11}$ Coseriu, «Introducción al estudio estructural del léxico», en Principios de semúntica estructural, Gredos, Madrid, pp. 132-133.
} 
Brocense $^{12}$ y A. M. Echaide ${ }^{13}$.

Por lo altamente ilustrativo y coincidente con nuestro pensamiento, nos permitimos hacer propio el texto de Echaide, que transcribimos literalmente:

«Como en toda oposición, según establece Greemberg, también, en la genérica el elemento no marcado puede incluir al marcado, pero nunca ocurre lo contrario. Como ejemplo sirvan las frases siguientes:

- El segundo hijo que ha dado a Avito Marina ha sido hija.

- El madrileño 3.000.000 [...] ha sido madrileña.

en las que sería imposible invertir los términos hijo e hija, madrileño y madrileña:

- La segunda hija que ha dado a Avito Marina ha sido hijo.

-*La madrileña 3.000.000 [...] ha sido madrileño.»

El elemento marcado de una oposición —el femenino en este caso- es más intenso y menos extenso que el no marcado —el masculino-. Y consecuencia de ello es que el elemento no marcado de la oposición —que puede funcionar como genérico en muchos casos- aparece con una frecuencia aproximadamente el doble de la que aparece el término marcado ${ }^{14}$.

Dado que el no marcado incluye siempre al marcado, y que en el nivel [+esp.] (donde se encuentra siempre el marcado) ambos se reparten opositivamente la sustancia del contenido, se puede concluir una ley del género, que diga más o menos así:

$i$. Entre dos términos que presenten oposición de género (como suele acontecer en el caso del sexo), el supraordinado será no-marcado por ser extensionalmente mayor.

ii.El número de frecuencias del término no-marcado es aproximadamente el doble del término marcado.

(4i) es lógico, puesto que, si volvemos la fórmula de (3), tendríamos que la frecuencia del término no marcado es equivalente al duplo de $a$, puesto que éste se repite en $\mathbf{A}$ como $\mathrm{a}_{1}+\mathrm{a}_{2}$. En un ejemplo concreto, niñol/niñola, el término no marcado niño tendrá una frecuencia de aparición aproximadamente el doble del término marcado niña, porque niño cubre las frecuencias de niño $=$ (varones + hembras), más las de $n i \tilde{n} o_{2}=(\text { varones solos })^{15}$.

De acuerdo con lo expuesto sobre los nombres [+anim., +sex.], creemos en la necesidad de distinguir dos clases de unidades:

${ }^{12}$ L.c., cap. VII.

${ }^{13}$ L.c., pp. 122-123.

${ }^{14}$ Echaide, o. c.

${ }^{15}$ Echaide constata ( $I b .$, p. 123 ) el $7.6 \%$ para el masculino y el $2,7 \%$ para el femenino. 

a. Monema $/ \mathrm{sexo} /$
b. Morfema /género/

y dos clases de estructuras de contenido, correlativas a los anteriores:
a. Campo léxico 'sexo'
(De orden lingüístico)
b.Campo gramatical 'género'.
(De orden metalingüístico)

Esta diferenciación explica, según creemos, que la heteronimia macho/hembra, hombre/mujer, gallo/gallina, etc., es fundamentalmente un problema de 'sexo' que implica el de 'género' gramatical. Se trata de simples cohipónimos o correlatos selectivos de sexo, del tipo «constante/constante», que pertenecen y se oponen dentro del mismo campo de experiencia. Nuevamente recurrimos a un diagrama, como (5), para representar esta idea.

Campo léxico: 'sexo'

\begin{tabular}{|c|c|c|}
\hline $\begin{array}{l}\text { Archilex.: } \\
\text { (dos microc: }\end{array}$ & impos) $\bigwedge^{\text {sexo }}$ & Archisemema1: 'sexo' \\
\hline Archilex. & macho / hembra & Archisem.2: 'M' / 'H' \\
\hline (Paradigma & & \\
\hline léxico): & $\begin{array}{l}\text { hombre/mujer } \\
\text { caballo/yegua } \\
\text { yerno/nuera } \\
\text { etc. }\end{array}$ & Sememas: (+hum., +M/H) \\
\hline
\end{tabular}

Así, cuando a un nombre como pantera, se le coloca el adyacente macho, lo que se hace es precisar semánticamente su extensión conformando o confinando la sustancia del contenido lexemático a una parcela de las dos que el campo del 'sexo' admite en su dimensión designativa ${ }^{16}$. Pero pantera, en cuanto palabra, sigue siendo gramaticalmente femenino. Lo prueba su capacidad de adjuntar determinantes y adyacentes femeninos:

La pantera macho lucía más cansadA (y no *cansado) que la pantera hembra ${ }^{17}$.

\footnotetext{
${ }^{16}$ Remitimos a la cita anterior de Coseriu.

${ }^{17}$ Nuestra conclusión parece contradecir al Brocense, quien cree ver un mecanismo de diferenciación de género en los nombres epicenos, en la añadidura de las palabras macho o hembra, (Minerva, cap. VIr, ed. cit., p. 62-63).
} 
En El País semanal del 12 de marzo de 1989,p. 42, apareció un curioso reportaje titulado «Tiburón blanco. El diablo del mar», en donde se observa este tratamiento léxico que terminamos de explicar, con la palabra tiburón. Es curioso cómo, aún refiriéndose a la hembra, conserva su género masculino. Dice así:

«...Tras él se sumaba un segundO tiburón al banquete, decididO a no compartirlo con nadie [...], una hembra de mucho mayor tamaño, con más de cinco metros de longitud y una tonelada de peso[...].

Estudiamos durante horas el comportamiento de aquella gran hembra, que desde entonces identificamos fácilmente [...].

Tal fue la violencia de algunos de sus embites que aparecieron lesiones en el puntiagudo y cónico morro del tiburón, así como en diversas partes de su anatomía...»

La distinción de un campo gramatiacal, cuya unidad es el morfema, tiene perfecto sentido dentro del campo sexuado. A él mejor que a ninguna otra esfera de la lengua puede aplicarse la ley hjelmsleviana de «participación» o inclusión ${ }^{18}$. En estos casos se trata de sustantivos flexionados en $-o /-a,-$ a los que sería lícito agregar los diferenciados por el artículo el/le, incluidos por Hjelmslev y Alarcos en la teoría de los morfemas $^{19}$, en cuyas expresiones al lexema corresponde la asociación del contenido del campo, mientras que solos los morfemas son los responsables de la diferencia de sexo. Así, en la oposición niño/niña, es preciso diferenciar niño, como [- esp.] que se opone a adulto, y niño, que se opone a niña.

Semánticamente:

-niño $/$ adulto $=([+$ ser hum.. tadulto $]) 1$

$\cdot$ niñ $\mathrm{O}_{2} /$ niñ $\mathrm{A}=([$ ser hum., 一adulto $]+[\mathrm{M} / \mathrm{H}])$

Gramaticalmente:

-niño, $/$ adulto $=$ ' $\mathrm{m}$ ' (fijo).

$\cdot n$ niñ $O_{2} / n i \tilde{n} A=' m / f '$.

Así como, semánticamente:

- potro, caballo $=([+$ equus, \pm adulto $])$

- potr $_{2}$ potrA $=([+$ equus, - adulto $]+[\mathrm{M} / \mathrm{H}])$

-pollo $/$ gallina $=([+$ ave $\mathrm{X}, \pm$ adulto $])$

- pollo ${ }_{2}$ pollA $=([$ +ave $\mathrm{X}$, -adulto $]+[\mathrm{M} / \mathrm{H}])$

Esto nos lleva a asumir para el español, 1) por una parte la existencia de un taxema de experiencia «sexo» diferenciado de otro taxema metalingüístico, e. d., «género», coincidentes en una misma expresión -a/-o, y 2) por otra parte, que la oposición sólo se presenta en esos dos taxemas si se los considera dentro del léxico marcado o

\footnotetext{
${ }^{18}$ Ensayos..., ed. cit., p. 283.

${ }^{19}$ Ensayos..., ed. cit., p. 210-211.
} 
especificado como [+esp.]. En este sentido, los morfemas - $o /$ - $a$ forman una clase de monemas especiales con capacidad lingüística y metalingüística.

La existencia - aparentemente indiscutible - de esta clase de morfemas o unidades monemáticas obliga a diferenciar entre:

(6)

$i$. Lexemas: unidades monemáticas lingüísticas.

ii. Gramemas: unidades monemáticas metalingüísticas. Y, entre estos, - Unos exclusivamente metalingüísticos (como las vocales «temáticas»)

- Otros no-exclusivamente metalingüísticos (como el género), con una vertiente de referencia en la realidad objetiva (p. ej., sexo) y otra en la gramática (el género) ${ }^{20}$

Es tan fuerte la tendencia cultural a diferenciar los sexos en español, que la lengua, con frecuencia, proyecta su sistema en el uso proporcionando el mecanismo de diferenciación y dando origen a creaciones analógicas (como en los casos de profesiones, favorecidas por la RAE) que han terminado por normalizarse ${ }^{21}$.

Así, la serpiente (culebra) en el texto de Ballester puede decirle a Eva: «Lo mismo me sucede a mí con mi culebrO»; lo mismo que en un texto venezolano sería perfectamente normal oír a alguien que insulta a una mujer extranjera con una expresión como: « $M u$ ushú $A^{22}$ tenías que ser!» O llegar a Santo Domingo y toparse con un caballero que busca a su caballerA. Y ¿Por qué no?, si en Venezuela también ovejo, alterna como supraordinado o genérico de la especie animal «ovino» con oveja ${ }_{1}$ cuyo macho es ovejo $_{2}$ y cuya hembra es oveja

En cambio, este fenómeno resulta inconcebible en los dominios de lo [-anim., -sex.], donde, por ejemplo, el universo no puede hallar su *universa, ni la estrella, su *estrello. Claro está que excluimos aquí los casos en que se haga uso de la prosopopeya, porque entonces, automáticamente nos estamos metiendo de nuevo en nuestro campo [+anim., +sex.]. En un cuento fantástico, perfectamente el Universo puede sentir su soledad porque le falta su Universa. Y esto demuestra con mayor rigor nuestra presunción de que el sexo constituye una motivación «fuerte» de género gramatical.

En el terreno de la política, del derecho y del trabajo, cada día estamos asistiendo a nuevas creaciones de este tipo. La razón estriba, sin duda alguna, en la integración de la mujer en la dinámica de la historia, que impulsa la exigencia de fijar esa parcelación real e ideológica lingüísticamente. Lo que hacen los hablantes es patentizar el contenido latente, potencial ${ }^{23}$, a través de las formas de expresión ya existentes, enriquecidas semánticamente.

${ }^{20} \mathrm{Cfr}$. K. Heger, Teoría Semántica, Alcalá, Madrid.

${ }^{21}$ Normalizar lo entendemos como incorporar a la «norma» linguística en el sentido de Coseriu, «Sistema, norma y habla», en Teoría del lenguaje y lingüística general, Gredos, Madrid, pp. 11 y ss.

${ }^{22}$ Ejemplos de esta naturaleza se pueden encontrar en Echaide (L.c., 4.11) y en A. Rosenblat, Buenas y malas palabras..., ya citada.

${ }^{23}$ Cfr. la obra de Hielmslev, Ensayos..., Gredos, Madrid, 1972, pp. 288 y ss. 
De ahí que, confundir sexo con género resulte fatal; pero no menos pensamos que lo es el negar su estrecha vinculación. Así que concluiremos afirmando (7):

(7)

$i$. El sexo es un taxema de experiencia que se diferencia esencialmente del género gramatical, pero sirve de motivación «fuerte» para él ${ }^{24}$.

ii. Para la clase de los nombres [+anim., +sex., +esp.], «sexo» implica siempre «género», conforme a las determinaciones:

$$
\begin{aligned}
& ' \mathrm{M}^{\prime} \rightarrow \text { 'm': (Macho implica (+) masculino) } \\
& \text { 'H' } \mathrm{'}^{\prime} \mathrm{f} \text { ' : (Hembra implica (+) femenino). }
\end{aligned}
$$

iii. En un nivel de no especificación o de hiperonimia, o sea, para la clase de nombres [+anim., +sex., —esp.], el «sexo» sigue subyacente, peroel «género» gramatical depende de otras motivaciones, porque el léxico se encuentra en zona de inmotivación semántica. Como no hay ' $M$ ' ni ' $H$ ', no se les puede aplicar estrictamente la ley de la participación hielmsleviana ${ }^{25}$; de ahí que tampoco se puedan dar las implicaciones de (ii).

Cuando en la lengua no hay una forma expresiva léxica o morfológica, el mismo sistema provee la determinación sintáctica a través del determinante (Art(ículo) o Dem(ostrativo)). Actualmente se observa un momento de fluctuación en que este sistema cede terreno a la expresión morfológica -o/-a.

Así, por ejemplo, cónyuges // ellla cónyuge, atleta // un/una atleta, etc.

Aunque algunos epicenos, como hormiga, alacrán, araña, etc. ${ }^{26}$, ofrecen gran resistencia a ello.

En el nivel genérico de lo sexuado, conocido como nombres comunes, o sea, nombres caracterizados como [+hum., +sex., —esp.], la oposición [el/la] asocia, a veces, otra información sustancial añadida como 'organismo profesional', 'rama de ciencia', etc.

Así:

- la policíall ellla policía $=$ ('org. prof.) $/ /(+$ hum., $+\mathrm{V} / \mathrm{H})$

-la químicall ell la químico $-a=($ "ciencia') $/ /$ ( + hum., $+\mathrm{V} / \mathrm{H})$.

Estos casos, sin embargo, son susceptibles de explicación dentro de nuestro esquema triangular hiponímico, como se aprecia sin gran esfuerzo.

${ }^{24}$ En este sentido creemos poder interpretar lo que la RAE dice en su Esbozo cuando se trata de la «Significación del género de los nombres de persona»: «Si los nombres sustantivos apelativos son de persona, tenemos la idea de que femeninos y masculinos, tal como acabamos de definirlos, designan respectivamente mujer y varón, o hembra y macho de algunas especies animales. Esta idea se acerca bastante a la verdad...» (p. 173).

${ }^{25}$ Ensayos..., p. 283.

${ }^{26}$ Sin embargo, véase A. M. Echaide: «Epicenos», 4.21, p. 116. 


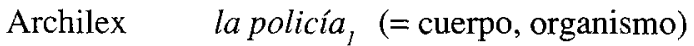

los policias (=varones y hembras)

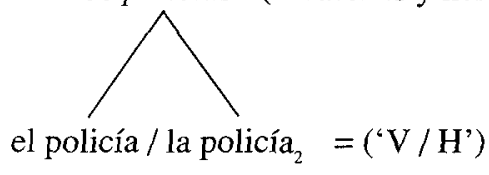

Todas estas deducciones habrán de ser tenidas en cuenta más adelante a la hora de determinar que la concordancia no es sólo un fenómeno de forma expresiva, sino que implica el manejo de la referencia interna o intratextual, que, de alguna manera, compromete la referencia lingüística.

De modo que, con justeza, podemos añadir que la determinación sintagmática del género no es otra cosa que una exigencia de la función fórica ${ }^{27}$, en virtud de la cual se afirma (8).

(8)

$i$. El sustantivo proyecta su género en todo el ámbito de la propia referencia como núcleo conformador de sustancia y forma. A esta caracterización la llamamos concordancia,

ii. En el plano de la forma, la marca de género es capaz siempre de manifestación homo y heterosintagmática, siendo su expresión con frecuencia redundante.

Volveremos sobre este asunto en otro estudio ya en curso sobre la definición formal del género.

${ }_{27}$ Definimos la función fórica como la función semántica de coherencia entre los elementos de un textoque remiten a un mismoreferente. Esta función seentiende en el textocomoanáfora, es decir, referencia de un elemento deíctico a un núcleo semántico, que constituye el centro de una zona de «dominio». Formalmente, dominio y anáfora se traducen en concordancia. 


\section{Referencias bibliográficas}

ANDERSON, James M. (1984), «The morphophonemics of gender in spanish nouns», en, Lingua, X (1961), pp. 285-296. Reprinted with permission of the North-Holland Publishing Company Amtserdam by Swets and Zeitlinger B. V. Lisse-The Netherlands-1984.

ANÓNIMO (1559), Gramática de la lengua vulgar de España, Ed. Faximilar de R. de Balbín y Antonio Roldán, Madrid, C.S.I.C., Clásicos Hispánicos, 1966, págs. 32-35: «Declinación del Artículo» y «Declinación del nombre».

BELLO, Andrés (1847), Gramática de la lengua castellana destinada al uso de los americanos. Con notas de R. José Cuervo. [Sobre la primera edición, publicada por primera vez en Santiago de Chile, 1847] Con «Introducción a los estudios gramaticales de D. Andrés Bello», Ministerio de Educación de Venezuela, Caracas, 1972, cap. X: «Género de los sustantivos».

CALONGE, Julio (1981), «Implicaciones del género en otras categorías gramaticales», Logos semantikos IV. Gramática. Studia linguistica in honorem Eugenio Coseriu 1921-1981, Madrid, Gredos, pp. 19-28.

CORREAS, Gonzalo (1627), Arte Kastellana. Introd., ed. y notas por Manuel Taboada Cid, Univ. de Santiago de Compostela.

ECHAIDE, A. M. (1969), «El género del sustantivo en español: evolución y estructura», en Íbero-Romania, I, 1969, pp. 89-124.

FERNÁNDEZ PÉREZ, Milagros (1987), «Importancia de las corrientes de investigación en la configuración de la «teoría linguíística»: un ejemplo de las llamadas categorias gramaticales», Verba, № 14, pp. 75-101.

GONZÁLEZCALVO, J. Manuel (1979), «El género, ¿una categoría morfológica?», en Anuaria de estudios filológicos, II, Universidad de Extremadura, Cáceres, pp. 51-73.

HJELMSLEV, L. (1934), Sistema lingüístico y cambio lingüístico, Madrid, Gredos, 1976.

IORDAN, lorgu y María MANOLIU (1972), Manual de lingüística románica, I, Madrid, pp 209 y ss. Tratan el tema en el cap. VII: «El sustantivo», y a partir del subtítulo 209: «La categoría de género».

KOVACCI, Ofelia (1977), Tendencias actuales de la gramática, Ed. Marymar, Buenos Aires, p. 9.

MARTÍNEZ, J.A. (1977), «Loselementos de la gramática y el género en castellano», Estudios ofrecidos a Alarcos Llorach, Univ. de Oviedo, pp. 165-192.

MATTOSO CÁMARA, Jr., J., Principios de Lingüística General, Librería Académica, Río de Janeiro, «Una categoría nominal: o género».

MEILLET, A (1951), Linguistique Historique et Linguistique Générale (comp.). Tome II, París, Livrairie C. Klincsieck.

NEBRIJA, Antonio (1492), Gramática de la lengua castellana, Ed. y estudio de A. Quilis, Madrid, Ed. Nacional, 1980.

-Estudio de Quilis, pp. 27 y ss.

- Gramática, pp. 164 y ss. 
RAMAJO CAÑO, Antonio (1987), Las gramáticas de la lengua castellana desde Nebrija a Correas, Salamanca, Universidad, Estudios filológicos 197.

ROSENBLAT, Ángel (1962), «Morfología del género en español», NRFH, XVI (1962), pp. 31-80.

SÁNCHEZ DE LAS BROZAS, Francisco (BROCENSE) (1587), Minerva o De la propiedad de la lengua latina. Introducción y traducción por Fernando Riveras Cárdenas, Cátedra, Madrid, 1976.

Sobre la edición [Francisci Sanctii Brocensis in inclita Salmanticensi Academia Primarii Rhetorices, Graecaeque linguae Doctoris Minerva: seu de causis linguae Latinae. Cum Licencia. Salmanticae, Apud Joannem, et Andream Renaut, Fratres, 1587]. Cap. VII: Del género de los nombres. No existen nombres de género común. Los nombres propios no tienen género.

TUSÓN, J. (1984), Lingüística, BARCANOVA, Barcelona, 5.4.5.: «El género», p. 105.

VILLALÓN, Licenciado (1558), Gramática castellana. Ed. facsimilar y estudio de Constantino García, C.S.I.C., Madrid, 1971, cap. III, pp [18][35].

XIMENEZPATÓN, Bartolomé(1614), Epítome de la ortografía latina y castellana. Estudio y ed. de A. Quilis y Juan Manuel Rozas, Madrid, C.S.I.C., Clásicos Hispánicos, 1965. Estudio de A. Quilis sobre el género:Nombre, pp. LXXXVII$\mathrm{XCI}$, y en «Instituciones de la Gram. Española», pp. 95 y ss.

ZENENKO, G.P. (1983), «Acerca de la manifestación del género de los sustantivos y adjetivos como categoría gramatical en las lenguas romances ibéricas», en Verba. Anuario Galego de Filoloxía, Vol. 10, 1983, pp. 231-247. 